\title{
Factors affecting successful induced lactation process among Malaysian women: a qualitative study
}

Norsyamlina Che Abdul Rahim

Institute for Public Health, Ministry of Health Malaysia, Putrajaya, Malaysia

Zaharah Sulaiman and Tengku Alina Tengku Ismail

Health Campus, Universiti Sains Malaysia, Kubang Kerian, Malaysia, and

Tahir Aris

Institute for Public Health, Ministry of Health Malaysia, Putrajaya, Malaysia

\begin{abstract}
Purpose - This qualitative study was to understand the factors affecting successful adoptive breastfeeding among women who underwent induced lactation process.

Design/methodology/approach - This study conducted in-depth interviews among induced lactation women in five states based on five regions [South (Johor), Central (Selangor), North (Penang), East (Kelantan) and East Malaysia (Sabah)]. The interviews have been consented, audio-recorded then transcribed verbatim, followed by identification of emerging themes.

Findings - Data saturation was achieved after interviewing a total of 23 induced lactation women. There were six main themes that emerged to describe factors affecting successful induced lactation process: (1) support and encouragement, (2) diet supplementation, (3) breastfeeding devices support, (4) incorporating treatment plan in the daily schedule, (5) high determination and pleasant attitude and (6) being informed on induced lactation process. Research limitations/implications - There can be recall bias among the respondents since the information was collected retrospectively, one to two years after the induced lactation practice completed. Due to that, we cannot rule out recall bias in the responses given in the interviews. In this study, induced lactation women barely were ethnic Malay Muslims. Thus, comparisons to other ethnic groups were not possible. This was due to the difficulty to get participation from induced lactation mother of other ethnic groups in the study. Even though the success is demonstrated, a significant limitation is that the ratio between Muslims and non-Muslims cannot be performed for the reason that the respondents only consists of Muslims alone.

Originality/value - The benefits of breastfeeding by an adoptive woman are numerous for both the mother and baby. There are multifactors involved in successful induced lactation process. After experiencing induced lactation, all respondents agreed that it has prepared them to be real mothers and breastfeeding is a pleasurable experience. All respondents corresponded to breastfeeding have a positive influence in the aspect of affection and touch. A mother who feels confident in her ability to lactate and is reassured by those around her will be most likely to feel successful in this great attempt.
\end{abstract}

Keywords Induced lactation process, Breastfeeding, Qualitative study, Malaysian women

Paper type Research paper

(C) Norsyamlina Che Abdul Rahim, Zaharah Sulaiman, Tengku Alina Tengku Ismail and Tahir Aris. Published in British Food Journal. Published by Emerald Publishing Limited. This article is published under the Creative Commons Attribution (CC BY 4.0) licence. Anyone may reproduce, distribute, translate and create derivative works of this article (for both commercial and non-commercial purposes), subject to full attribution to the original publication and authors. The full terms of this licence may be seen at http://creativecommons.org/licences/by/4.0/legalcode.

The authors would like to thank the Director General of Health Malaysia for permission to present this study.

Funding: The authors received no financial support for the review, authorship and/or publication of this article.

Declaration of Conflicting Interest: The authors declare no potential conflicts of interest concerning the research, authorship and/or publication of this article.

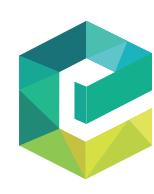

British Food Journal Vol. 122 No. 10,2020 pp. $3049-3063$ Emerald Publishing Limited DOI 10.1108/BFJ-03-2020-0254 
$\mathrm{BFJ}$

122,10

3050

\section{Introduction}

Induced lactation is a method of stimulating the production of breast milk in women who have not gone through the process of pregnancy (Szucs et al., 2010). Recent advances in technology have allowed such women to breastfeed their adopted children. Previous studies conducted in Western countries have commonly explored the breastfeeding of adopted children, as well as the experiences, successes and challenges of this process. Despite the wealth of literature available in the field, there is a lack of clarity due to limited studies on induced lactation practice in Malaysia. To date, there is no induced lactation national data available, although most hospitals and health clinics in Malaysia have provided induced lactation services in their respective places Zilal and Farahwahida (2014) stated that it is difficult to determine the actual number of women who have undergone procedures to induce lactation in Malaysia. However, with the rising awareness and demand in adoptive breastfeeding, practitioners in Malaysia have been treating adoptive women who intend to become nursing mothers accordingly and depending on the mothers' situation.

Malaysia is a multicultural society that includes ethnic Malays, Chinese and Indians. However, child adoption is common in this multiethnic society. The number of applications for registration and adoption of children from year to year has increased significantly. In 2015, the total adoption rate was 1927, while in 2016, it increased to 2,354 (Social Welfare Statistics Report, 2016, 2017). Analysis done by the National Registration Department in 2011 showed that the highest number of adoption applications were submitted by Malay couples $(n=3,418)$, followed by Indian $(n=286)$ and Chinese $(n=229)$ couples. Punjabis and natives from Sabah and Sarawak states also presented numerous applications for child adoption $(n=1,595)$ (National Registration Department, 2012). The National Lactation Centre of the Ministry of Health Malaysia reported that only 24 mothers underwent induced lactation in 2013 (National Lactation Centre, 2015). However, increased numbers have been reported in $2014(n=68)$ and $2015(n=52)$ (National Lactation Centre, 2016 and 2014). In general, prior work is limited to a subset of published data about induced lactation protocols or procedures in Malaysia except for one study by Zilal et al. (2017) involving 12 nonpuerperal Muslim females who had successfully nursed their adopted children. Zilal et al. (2018) revealed that support system, advice and consultation, equipment, time management and diet and nutrition were the main factors affecting success in induced lactation.

Many women claimed that the ability to breastfeed their adopted child makes them feel more accomplished as women and mothers. It was found that such an approach creates betters maternal-infant bonding between the adopted child and parent (Flores-Antón et al., 2017). Induced lactation has been embraced to provide an enhanced love bonding experience for women adopting babies. Some studies have found that breastfeeding benefits were strong bonds between mothers and children (Gribble, 2007) to meet the nutritional needs of babies who were carried by surrogate mothers (Auerbach and Avery, 2007; Kinga et al., 2010); and wet nursing is an obstacle to marriage between siblings who are breastfed by the same mother (Zilal and Farahwahida, 2014).

Inducing lactation is a way to provide an enhanced bonding between the adopted child and adoptive mother. Unfortunately, milk production is always insufficient to breastfeed the child exclusively. Nonetheless, women find satisfaction in this rigorous process because of the maternal adhering with the child that it promotes (Sharan et al., 2001). According to Ezura Mariana et al. (2015) from the breastfeeding support group, Susuibu.com reported that only $47.2 \%(N=17)$ of women were successful in induced lactation process. Meanwhile, others failed to give breast milk to their adopted children. These adoptive mothers coming to healthcare centers that offer induced lactation services showed the determination of them to provide the best food for their adopted children. This study can be considered to be a significant step forward in understanding the factors affecting successful induced lactation 
process among women who underwent induced lactation process in Malaysia. This study has made a substantial contribution to help other women and their spouses/partners in comprehending the challenges, obstacles and support that are needed along with the initiation of the induced lactation process.

\section{Methods}

\section{Study design and setting}

This study is a qualitative research design using a purposive sampling method carried out on

23 women who had been nursing their adopted child. The locations of this study involved five regions representing the East Region, the North Region, the South Region, Central Region and East Malaysia/Borneo. A state was selected from each region randomly. The randomly selected states for data collection were Kelantan, Penang, Johor, Selangor and Sabah.

\section{Sample}

The selection of women who underwent induced lactation procedure was obtained from the institutions involved in conducting the breastfeeding consultation such as lactation centers, hospitals and health clinics. Sample size is estimated based on the concept of saturation for qualitative research (Ritchie and Lewis, 2003). The saturation occurs when new data collection no longer contributes to further information on the issues under investigation. Data were collected for a period of 36 months from June 2015 to July 2018. The inclusion criteria of respondents were woman never been pregnant; did not have a biological child; adopted a child within two years according to the lunar month calculation during data collection; without breastfeeding experience; were undergoing induced lactation procedure (completed or still under treatment) and successfully nursed the child until he/she is fully satisfied for five sessions or more (based on Islamic laws which proclaim relationship of mahram).

\section{Data collection}

The method of collecting data was semistructured face-to-face interview. Semistructured interviews were conducted using open-ended questions that addressed support and encouragement, treatment plan in the daily schedule, difficulties during the process, motivational and demotivational factors, feelings and thoughts and an evaluation of the entire process (Kallio et al., 2016). We prepared the interview guide (Table 1), and we established the interview questions following previous classic studies (Auerbach and Avery, 1981; Hormann, 1977; and Thearle and Weissenberger, 1984). It is intended to provide a comprehensive understanding of the experiences of women undergoing these processes. Interviews were conducted in the Malay language because most of the respondents were Malays, and they understood and preferred the language. For this study, most of the interviews with the induced lactation women had been conducted at their houses. The respondents provided written consent, and brief sociodemographic information priority to the interview sessions confidentiality and anonymity of ethics were maintained. All interviews were conducted for approximately 45-90 min for each session.

\section{Data analysis}

The interviews were recorded, and the study data were systematically documented. These interview transcripts were then analyzed using ATLAS.ti Version 8 software. In this study, thematic analysis was used for data analysis. The thematic analysis focuses on the human experience subjectively. In the thematic analysis, themes were identified at the manifest level or the latent level-semantic or latent (Boyatzis, 1998). This analysis represents a systematic framework to code qualitative data in order to recognize patterns across the data (Braun and Clarke, 2014). There are several discrete steps involved in thematic analysis, including 


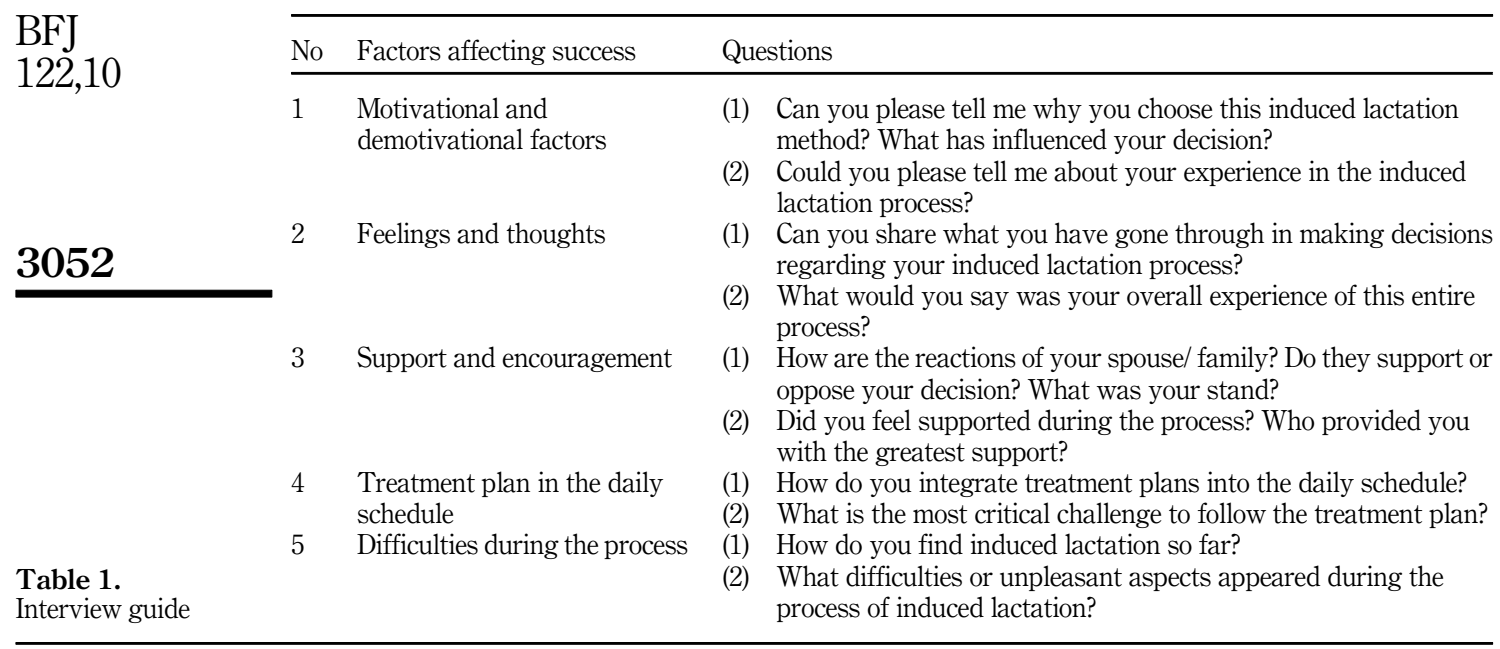

familiarizing oneself with the data, generating initial codes, searching, reviewing and finally, defining themes (Braun and Clarke, 2014).

Various methods or procedures used and called triangulation, which serves to clarify meaning by identifying different approaches of the same phenomenon using multiple sources of evidence. In order to enhance the research credibility in this study, researchers applied triangulation from various sources. The interview, as the primary data, was supported by the secondary data from home and hospital-based information sheets to ensure the accuracy of information. Any discrepancies between the events reported in the information sheet and the information obtained during the interview were checked. Next, the member checking process was done by phone calls, and the polished content of the transcripts and the quotations cited were read to the respondents. Rich, thick description was used to provide many perspectives about a theme so that the results become realistic and richer.

\section{Ethical approval}

Ethical approval for this study was obtained from the Medical Research and Ethics Committee, Ministry of Health Malaysia with code NMRR-15-1600-26147 (IIR) and Human Research Ethics Committee Universiti Sains Malaysia with code Project USM/JEPeM/ 14044139 .

\section{Results}

\section{Respondent characteristics}

Out of 23 women (respondents) undergoing induced lactation procedure, six respondents were housewives (26.0\%), and 17 respondents were working $(74.0 \%)$ (Table 2). In this study, all the respondents were ethnic Malay Muslims. Respondents were aged 26-40 years. Three respondents had two adopted children (one respondent had a twin as adopted children). The others only adopted one child. In total, 25 children were adopted from 23 respondents. In terms of adopted children's gender, 14 children were boys (53.9\%), and 12 children were girls $(46.2 \%)$. The adopted children's age when the interview was conducted ranged from 20 days to 24 months. 


\begin{tabular}{|c|c|c|c|c|c|c|c|}
\hline Respondents & Region & $\begin{array}{l}\text { Age } \\
\text { (year) }\end{array}$ & Occupation & $\begin{array}{c}\text { Duration of } \\
\text { marriage } \\
\text { (year) }\end{array}$ & Adopted & $\begin{array}{l}\text { ild } \\
\text { Age of child } \\
\text { during interview } \\
\text { (month) }\end{array}$ & $\begin{array}{r}\text { Induced } \\
\text { lactation } \\
\text { process }\end{array}$ \\
\hline A1 & Central & 37 & Housewife & 8 & Girl & 5 & \\
\hline A2 & Central & 32 & Housewife & 11 & Girl & 8 & \\
\hline A3 & Central & 38 & Teacher & 12 & Boy & 12 & 3053 \\
\hline A4 & Central & 38 & Lecturer & NA & Girl & 12 & \\
\hline A5 & Central & 38 & Liaison officer & 9 & Girl & 19 & \\
\hline A6 & Central & 33 & Lecturer & 8 & Boy & 24 & \\
\hline A7 & North & 27 & Housewife & 4 & $\begin{array}{l}\text { Boy and } \\
\text { Girl } \\
\text { (twin) }\end{array}$ & 19 & \\
\hline A8 & North & 34 & Housewife & 5 & Boy & 2 & \\
\hline A9 & North & 36 & Teacher & 12 & Boy & 3 & \\
\hline A10 & North & 34 & Teacher & 10 & Boy & 12 & \\
\hline A11 & North & 40 & Librarian & 13 & Girl & 24 & \\
\hline $\mathrm{A} 12$ & South & 38 & Nurse & 12 & Girl & 8 & \\
\hline A13 & South & 34 & Industry officer & 9 & Boy & 4 & \\
\hline A14 & South & 31 & Housewife & 7 & Girl & 4 & \\
\hline A15 & South & 29 & Lecturer & 4 & Girl & 4 & \\
\hline A16 & East & 40 & $\begin{array}{l}\text { Administrative } \\
\text { assistant }\end{array}$ & 13 & Girl & 24 & \\
\hline A17 & East & 30 & Accountant & 9 & Girl & 20 days & \\
\hline A18 & East & 34 & Safety guard & 7 & Boy & 20 days & \\
\hline A19 & East & 26 & $\begin{array}{l}\text { Assistant } \\
\text { pharmacist }\end{array}$ & 5 & Boy & 1 & \\
\hline A20 & East & 36 & $\begin{array}{l}\text { Medical laboratory } \\
\text { technologist }\end{array}$ & 9 & Boy & 20 & \\
\hline A21 & $\begin{array}{l}\text { *East } \\
\text { Malaysia }\end{array}$ & 35 & Nurse & 10 & Girl & 2 & \\
\hline A22 & $\begin{array}{l}\text { *East } \\
\text { Malaysia }\end{array}$ & 37 & Teacher & 10 & Boy & 1 & $\begin{array}{r}\text { Table } 2 . \\
\text { Descriptive }\end{array}$ \\
\hline A23 & $\begin{array}{l}\text { *East } \\
\text { Malaysia }\end{array}$ & 36 & Housewife & 15 & $\begin{array}{l}\text { Boy } \\
\text { (Twin) }\end{array}$ & 12 & $\begin{array}{r}\text { Descriptive } \\
\text { characteristics of } \\
\text { induced }\end{array}$ \\
\hline \multicolumn{7}{|c|}{ Note(s): *East Malaysia: Sabah and Sarawak } & lactation women \\
\hline
\end{tabular}

The mean duration of marriage (year) among couples was nine years (ranged from 4 to 15 years). Seven respondents were married for more than ten years, 15 respondents were married for less than ten years, while one respondent was single and not married. Those who were married for more than ten years were all 30 years and above. Out of 15 respondents who were married below ten years, three of them were in their 20's while another 12 were in their 30 's. They were in their reproductive age, which is 26-40 years old.

\section{Factors affecting successful induced lactation process}

Based on the interviews with 23 respondents, various factors were influencing the success in induced lactation. The factors emerged among the respondents were (1) support and encouragement, (2) diet supplementation, (3) breastfeeding devices support, (4) incorporating treatment plan in the daily schedule, (5) high determination and pleasant attitude and (6) being informed (Table 3). The most commonly mentioned factor by the respondents was support and encouragement from various parties. Respondents had limited exposure to the 
$\mathrm{BFJ}$ 122,10

\section{4}

Table 3.

Thematic analysis results for factors affecting successful induced lactation process knowledge of induced lactation protocols and procedures, which frequently led to further problems after adoption.

\section{Support and encouragement}

In line with the findings of previous studies, even though the respondents who were unable to breastfeed their babies exclusively, they are still able to breastfeed if excellent support is provided. Majority of respondents obtained support from their husband during the process of induced lactation. Respondents also agreed that they obtained complete support from other family members. The supporting husband's sign was expressed as "husband gives support," "husband is helpful," "husband takes care of me when I am producing milk," "husband supports me financially," "husband helps to prepare the equipment," "husband helps to massage me."

One respondent mentioned that she was given time and space to express her milk through her sister's support:

My sister helps to babysit especially when I am pumping my breast. She also teaches me how to do stimulating massage to produce breastmilk. (Woman A10)

To get help in ensuring successful breastfeeding, one of the respondents decided to stay with her mother for a month to get support in taking care of her small baby:

My husband. . .my mother gave me supports to take an adoption. At night I stay with my mother. Almost for a month, I stayed with her. During the day, my husband comes, and he helps me too. I do not know how to handle the small baby alone, so my mom teaches me this and that. (Woman A16)

Most of the respondents agreed that their financial resources came from their husbands. As being mentioned by one of them:

\begin{tabular}{ll}
\hline Subtheme & Theme \\
\hline (1) Giving mother personal time for relaxation & (1) Support and encouragement \\
(2) Help with housework & \\
(3) Sharing accountability & \\
(4) Help provide daily necessities and breastfeeding equipment & \\
(5) Assistance while breastfeeding & (2) Diet supplementation \\
(1) Practicing balance diet & \\
(2) Taking herbs and enough fluid & (3) Breastfeeding devices support \\
(3) Consuming food supplements & \\
(1) Using supplemental feeding tube device & (4) Incorporating treatment plan in the \\
(2) Using breast pumps & daily schedule \\
(3) Using a cup or syringe or bottle to feed a baby & \\
(1) Planning at work & \\
(2) Recognize an imbalanced workload at workplace & \\
(3) Setting the pumping schedule & (5) High determination and pleasant \\
(4) Distribution of duties with a spouse or other family members & attitude \\
(5) Readiness to seek for help & \\
(1) Committed to the process of induced lactation & \\
(2) Willingness to keep trying & \\
(3) Strong desire for success / High determination & (6) Being informed \\
(4) Optimistic & \\
(5) Always calm and having patience & \\
(1) Learn about breastfeeding techniques & \\
(2) Finding information on induced lactation methods & \\
(3) Perform an induced lactation process with the advice and & \\
&
\end{tabular}


Right now, I am having no problem financially since my husband supports all the expenses. (Woman A7)

She also stated that her husband helped her a lot during the process of induced lactation, as being mentioned in examples below:

My husband supports me to breastfeed, and he gives me back massage every night. The midwife told me that I need to get back massage to increase milk production. She teaches my husband how to do that. While I am pumping my breast, he gives me a massage. (Woman A7)

However, there were some negative reactions to the efforts done to induce breast milk reported by respondents. In addition to the negative view of society, some of the respondents also received an objection from their family:

There are some negative-minded people that do not know unpregnant women can breastfeed. They cannot believe that we can breastfeed even without getting pregnant. (Woman A11)

One of the respondents that had successfully breastfeed her child said that supports from employers and colleagues were essential:

I have no problem at my workplace, my job issues, my employer, my environmental issues.

Everything is good. Everybody knows that I am breastfeeding, and they gave me good support.

This is one of the reasons why I was able to breastfeed my adopted son successfully.

(Woman A20)

\section{Diet supplementation}

Most of the respondents were taking balanced diet and supplements to increase milk production. However, the narratives revealed no specific food that could help to increase milk supply. This is because of the effectiveness of specific diets and tips depends on an individual's body.

The respondents believed special food items containing galactagogues were one of the options for improving human milk supply and supporting breastfeeding. The food items stated as radish, dates, fenugreek, turnip, ginkgo, goat milk, almond, carrot and mustard.

Some respondents said that consumption of radish, milk tea and almonds in addition to a balanced diet helped them to increase their milk production as illustrated below:

I eat radish, dates and milk. I also drink fenugreek-soaked water and eat mustard. I do notice that if I eat white radish, my milk increases. Ialso drink Horlicks sometimes. These days I only eat a balanced meal. (Woman A3)

While some of them mentioned that intake of milk, chocolate drinks, fenugreek and vegetables helped them to increase milk production:

I take almond. I make almond milk or eat it raw. I also take fenugreek and milk tea continuously. Every day I cook radish, making soup and Masak Lemak. It is beneficial besides taking a balanced diet. (Woman A4)

Nonetheless, some of the respondents had tried taking various kinds of food to boost milk production, but it was still ineffective:

I take goat milk, turnips and ginkgo juice. I do not really like Gingko juice, so I do not drink it that frequent. The previous day I ate oat, but it did not work. I also take fenugreek in the form of pills. I have tried eating and drinking many things, but my milk does not increase. (Woman A9) 
BFJ

122,10

3056

\section{Breastfeeding devices support}

In many instances, respondents reported using special devices to help them overcome various breastfeeding problems. Some of the respondents in this study said that the child could breastfeed directly with the help of the supplemental feeding tube device or supplementary nursing system (SNS). They stated as below:

After taking a foster child, I started giving her breast milk straight away, but by using a tube tool (not direct latches), then she will drink my milk. I would squeeze my nipples. At that time, I had no intention to buy milk pumper. (Woman A2)

Another respondent remarked.

She wants to drink milk when I use that tube. When I mix the milk, she wants to drink it. That tube helped me to produce milk faster even at that time. I did not buy a pump yet. I would squeeze my nipples during bath and milk started to come out. (Woman A2)

Anyhow, some respondents stated that their babies prefer to feed by a bottle rather than using other breastfeeding devices:

At first it was okay when I used SNS, but after I start to feed her with the bottle, she did not want to suck the tube tool anymore, maybe because the tube is so small, it's hard for suckling. Bottles are much easier. (Woman A2)

There was a respondent that used a syringe to help her deliver the breast milk to the baby. It is being mentioned in the statement below:

My nipple is still small. So, I made a syringe in $50 \mathrm{ccs}$ and I strapped it around the neck. I made it with my friend. This tool will help as if it is near the baby's lips. I made its own tubing. Then I cut this long, and then I took one clamper. I put into the tube then I clamped it. So, when the baby does not suck, it does not overflow. If not, it will flow freely. It is beneficial for me at the start of breast stimulation to produce milk. (Woman A12)

\section{Incorporating treatment plan}

The narratives revealed six aspects of management that respondents pay attention to in order to succeed in breastfeeding: "planning at work," "recognize an imbalanced workload at workplace," "setting the pumping schedule," "distribution of duties with spouse" and "readiness to seek for help."

One of the respondents recognized an imbalance workload and demanding to be freed from any commitment at the workplace:

I am occupied with work and all other things that I need to handle. I am asking my sister-in-law to stay at my house to help me with house chores and babysitting. For that semester, I am demanding to be freed from any commitment or becoming a committee member since it will become my constraint. Usually, I am one of the committees, but I refused it for this semester because of the workload, and I really need this. (Woman A4)

Getting help from a family member can make the daily obligation easier and give a woman a chance to continue the process of induced lactation:

My husband supports me. My husband and my mother too. My mother is so supportive. When I go to work, she will take care of the baby. I returned home from work sometime at seven o'clock, need to perform Maghrib prayers and so on, must do pumping at 8 o'clock. Then I must pump at 9. I need to catch up on time. Sometimes the baby wants to change clothes at night. My mother usually helps to bath the baby in the evening. (Woman A12) 
Most of the respondents acknowledged that the husbands' assistance in doing house chores gave them some spaces to relax and continue the process of induced lactation:

Most are done by my husband. He stays up at night, sometimes gets up for milk. He must put it in the bottle and use that tool (SNS), yes. He really helps me a lot. Even on holidays, he helps with house chores a lot. So, I can spend more time with my baby and do the milking. (Woman A15)

The distribution of work among colleagues at the office is also acknowledged by many respondents as a factor helping them to succeed in breastfeeding:

In terms of employer, workplace, I am not having problems. Like my boss, she said if I want to do the pumping, it is okay, and she will cover for me for a few minutes. No problem. My attendant also understands my situation at that time. We cover for each other. (Woman A10)

Setting a pumping schedule is also one of the best efforts for time management and has been acknowledged by one of the respondents:

Well, maybe because of my effort, for being consistent with doing the pumping, eight times a day. But that day, I got $5 \mathrm{ml}$ even when I am not pumping for eight times, only pumps at school for a few times, at night for a few times more. I try to adjust the pumping time at school and at home to make sure the milk is still there. (Woman A22)

\section{High determination and pleasant attitude}

From the analysis of the data it was found that all the respondents have a highly desire to breastfeed their adopted child. Throughout the interview, majority of the respondents have said that "I want," "I am really intended to," "I desire to," "I am really wanted to" and "I have goals to be achieved and satisfaction." They expressed this feeling as:

I am really determined from the start that if I am taking an adoption, I will breastfeed the baby. (Woman A14)

Many respondents said that every mother should always be positive and stay motivated so that milk can be easily produced. They expressed their feeling as below:

We have to stay positive. As the doctor says, we must set in mind our goals so that by the time we will feel calm and the milk will start to come out, little by little. (Woman A11)

Some respondents were willing to try for the second time after failing the first attempt to prove their determination to undergo the process of induced lactation. One of the respondents said:

I am determined to breastfeed the baby. I do not care what happened. I have tried once but failed. But this time I am determined to breastfeed my baby no matter what. (Woman A10)

\section{Being informed}

The respondents need to understand how this process occurs, following the appropriate protocol and implementing breast stimulation with discipline. The secret to achieving successful breastfeeding was very much dependent on the mother's preparation in the perspective of knowledge and experience. However, these had become the main challenge for women who adopted children and had the intention to breastfeed the child.

One respondent mentioned that knowledge related to childbirth and breastfeeding is essential especially in induced lactation as it is different from that of a pregnant woman and giving birth:

We need to know about adoption processes. Knowledge about breastfeeding is a must too. Since breastfeeding in adoptive mother is different from biological mother, right? That's all we need to have before we can start adopting kids. (Woman A10) 
$\mathrm{BFJ}$

122,10

In addition to that, get a consultation from a breastfeeding counselor who is expert in breastfeeding:

Consulting with the right people is the right thing to do. Or you can make someone that was succeeded as your mentor, because sometimes, for me, I need someone to guide me. Ineed someone to be a good example, do not want a negative example. (Woman A6)

One of the respondents also stated that her milking skills were obtained from a lactation consultant she ever met at the hospital:

Yes, Ilearnt there. They show us how to express milk by hand. After sometimes, I prefer to use hands more than milk pumps. Thank God I produce so much milk. (Woman A15)

Most respondents agreed that they got the correct knowledge related to breastfeeding from lactation counselors, as in the example below:

At first, I do not know how to do it. Imet staff nurse $R$ to learn about breastfeeding techniques, how to hold him. The staff nurse told me not to give a bottle as the baby will be confused. (Woman A8)

\section{Discussion}

The process of induced lactation obliges considerable dedication and determination. It is a far more arduous task than initiating postpartum lactation, but it is possible and worth the effort, according to the many who have attempted it. Da Rocha et al. (2014) stated this process requires an endeavor and hard work that can be stressful but rewarding when a mother can breastfeed her adopted child successfully. Accordingly, there are six factors closely related to the factors affecting success, i.e. mothers should have support and encouragement, dietary supplementation, breastfeeding devices support, incorporating treatment plan in the daily schedule, high determination and pleasant attitude and mothers had been informed about induced lactation process. These findings are in line with those found in the literature, where induced lactation cessation is a complex issue that is influenced by biophysical factors (pain, nipple injury and insufficient milk), psychosocial factors (maternal motivation and confidence, breastfeeding knowledge, family support and breastfeeding intentions), hospital practices (delayed initiation of breastfeeding, early formula supplementation and delivery interventions) and sociodemographic factors (household income, maternal education level and return to work) (Gribble, 2007; Kinga et al., 2010; Zilal and Farahwahida, 2014; Barbosa et al., 2017). Zilal et al. (2018) also revealed that support system, advice and consultation, equipment, time management and diet and nutrition were the main key success in induced lactation.

\section{Support and encouragement from spouse, family members and health professionals}

Most respondents emphasized that the main factor affecting their success for attempting induced lactation was about support and encouragement from spouse and family members. These results agree well with existing studies on 235 participants who had achieved exclusive maternal breastfeeding with a high level of motivation with the help of medication supply; support and encouragement ensure the success of breast milk stimulation and therefore becomes a significant factor of the adoptive breastfeeding success (Goldfarb, 2009). Participants in her study reported a successful $(71 \%)$, satisfied $(71 \%)$, overall experience and given the opportunity would induce lactation again (83\%). Adoptive breastfeeding was challenging to achieve in practice without the support system from numerous parties (Zilal et al., 2018). These results are consistent with findings reported by Lommen and Brown (2015) and concluded that the support that women received from breastfeeding services and their families enabled them to breastfeed their babies. Flores-Antón et al. (2017) described moral 
support from the husband, and the immediate family can increase the mother's motivation and spirit to complete the induced lactation process. Besides, the mother placed great importance on the emotional support offered by lactation consultant too. Mothers who choose to increase lactation will need more support and encouragement in their efforts from spouses, families and health professionals. It, therefore, appears that emotion and psychology are essential factors in term of oxytocin secretions influencer, therefore self-confidence and a strong desire to succeed in induced lactation (Norsyamlina et al., 2017).

\section{Strong commitment and determination to breastfeed adopted child}

The respondents for this study showed a strong commitment and determination to breastfeed their adopted child, often continuing despite initial or ongoing complexities and possessing both the motivation and "social capital" to seek out additional support. Most of the respondents arrived that they attempted to breastfeed an adopted child was about maternalinfant relationship and its enhancement through breastfeeding rather than milk production. The spirit and attitude of the mothers have shown that it is a factor in the success of breastfeeding an adopted child. Gribble (2004) found that motivation was needed by all mothers who wanted to perform lactation. Thus, the findings of Zilal et al. (2017) study detail the aspects of motivation related to attitude and spirit to succeed in adoptive breastfeeding. Researchers equate the lactation process with everyday life, where positive attitudes are followed by a strong desire to achieve success.

\section{Nutrition plays an essential role in breastfeeding}

Mother's diet will affect the content of her breast milk. Most of the respondents were taking balanced diet and supplements to increase milk production. The respondents believed special food items containing galactagogues were one of the options for improving human milk supply and supporting breastfeeding. Galactagogues have been widely used to encourage and maintain breastfeeding, including in the cases of premature babies, adopted child and surrogate mothers (Wittig and Spatz, 2008). The food items stated by respondents were radish, dates, fenugreek, turnip, ginkgo, goat milk, almond, carrot and mustard. However, the results of the interview found that there was not a single type of food and drink that ensured the success of lactation. This is because of the effectiveness of certain diets and tips depends on an individual's body. Several herbs/supplements are purported to increase breast milk production have been reportedly used by intended mothers to help them adoptive breastfeed. Of these, fenugreek seed, blessed thistle, and goat's rue are some of the more popular ones. Many other ingredients, such as fenugreek, blessed thistle, milk thistle, fennel, alfalfa, oats, and marshmallow root, have been reported to help with breastfeeding, but research is inadequate (Kinga, 2010).

\section{Existence of technology for aiding induced lactation process}

One of the factors identified in this study is the existence of technology in terms of exposure and tools for aiding induced lactation mothers to produce breast milk without prior pregnancy and birth. This factor is in line with the other two studies by Chelsea-Siebenalar (1999) and Goldfarb (2009). The factor that drives success in induced lactation is the equipment used to facilitate the process of lactation. It consists of supplementary nursing tool and breast pump. Most of the respondents used both types of equipment. The ability to produce milk as a reason for these women wanted to breastfeed their adopted child until it succeeds.

\section{Time management}

Efforts to produce milk by women who have never been pregnant and give birth are not accessible. They need to take into account several factors before joining an induced lactation 
$\mathrm{BFJ}$

122,10

program since the needs of everyone are different. Therefore, the respondents need to arrange and manage their time wisely to meet the objective of lactation within a certain period. Comparing the results with Zilal et al.'s (2018) study indicated that time management involved three things, i.e. take the unpaid leave, time to express milk and time to give breast milk to the baby. Kinga et al. (2010) reported similar observations in their study that the success of breastfeeding reflects the careful planning of the adoptive mother from the early days, her active role in the hospital stay, and the support of health care staff and family members. Some respondents acknowledged that the most critical challenge was to be consistent in stimulating their breast milk due to their inability to follow the treatment plan. Theoretically, the basic concept and procedures for inducing lactation seemed straightforward, but in practice, several respondents face severe difficulties.

\section{Understanding the concept of induced lactation procedure}

Unlike data form previous studies, the study showed that many respondents remain unfamiliar with the techniques, preparation and support required to induce lactation successfully. According to World Health Organization (2017) poor breastfeeding techniques associated with unsuccessful breastfeeding, indicating that adequate breastfeeding support, including evaluation of latching, position and feeding at the breast, could prevent nipple cracks and mastitis. In order to improve knowledge, every woman is advised to meet face to face with a certified medical practitioner, lactation consultant or lactation counselor to get a comprehensive overview of the process she will undergo to induce lactation (International Board of Certified Lactation Consultants (IBCLC) Malaysia, 2015). Medical practitioners can help mothers by providing knowledge on how the techniques effectively worked in order to successfully perform this unique desire (Bryan, 2006). Direct consultation with experts gives women a much clearer picture of the available options and a fuller understanding of the best practices for induced lactation. This argument is consistent with the finding found in the literature, where many of the respondents interviewed stated that breastfeeding knowledge related to childbirth and breastfeeding is fundamental especially in induced lactation as it is different from that of a pregnant woman and giving birth. The efforts and commitment of all respondents in gathering information designate that the importance of knowledge for induced lactation should succeed (Norsyamlina et al., 2017).

\section{Strength and limitation of the study}

The main strength of this study is that we have conducted this study across Malaysia, which represents the five regions. Women in the current sample reported having no children of their own; however, as questions primarily focused around societal attitudes toward adoptive breastfeeding, the nulliparous sample was able to offer unique perspectives related to perceived social norms of breastfeeding. This study also used primary data that should consider strength. However, there can be recall bias among the respondents since the information was collected retrospectively, one to two years after the induced lactation practice completed. Due to that, we cannot rule out recall bias in the responses given in the interviews. In this sense, it is possible that the reported adoptive breastfeeding rates overestimated the actual rates. In this study, induced lactation women barely were ethnic Malay Muslims. Thus, comparisons to other ethnic groups were not possible. This was due to the difficulty to get participation from induced lactation mother of other ethnic groups in the study. Even though the success is demonstrated, a significant limitation is that the ratio between Muslims and non-Muslims cannot be performed for the reason that the respondents only consist of Muslims alone. 


\section{Conclusion}

The benefits of breastfeeding by an adoptive mother are numerous for both the mother and baby. There are multifactors involved in successful induced lactation process. Adoptive mothers need to understand how this process works, follow the appropriate protocols, and implement breast stimulation with discipline. The cooperation of the adoptive mother and baby is also crucial in the course of the breastfeeding process. After experiencing induced lactation, all respondents agreed that it had prepared them to be birth mothers and breastfeeding is a pleasurable experience. All respondents corresponded that breastfeeding has a positive influence on the aspect of affection and touch. A mother who feels confident in her ability to lactate and is reassured by those around her will be most likely to feel successful in this great attempt. However, there are many factors to be considered in induced lactation programmes, due to adoptive mothers' varying religious and ethnic backgrounds, health status, financial and environmental challenges. In short, being successful in induced lactation is not impossible, and it could be improved to an optimal extent by employing several techniques and established preparation that is aligned with the current situation. In future work, it may be useful to propose the large-scale longitudinal studies to evaluate the effects of breastfeeding on the relationship of the adoptive child to her adopted family.

\section{References}

Auerbach, K.G. and Avery, J.L. (1981), "Induced lactation. A study of adoptive nursing by 240 women", American Journal of Diseases of Children, Vol. 135 No. 4, pp. 340-343, doi: 10.1001/ archpedi.1981.02130280030011.

Barbosa, G.E., Silva, V.B., Pereira, J.M., Soares, M.S., Medeiros, R.D., Pereira, L.B., Pinho, L. and Caldeira, A.P. (2017), "Initial breastfeeding difficulties and association with breast disorders among postpartum women”, Revista Paulista de Pediatria, Vol. 35 No. 3, pp. 265-272.

Boyatzis, R.E. (1998), Transforming Qualitative Information: Thematic Analysis and Code Development, Sage Publications, Thousand Oaks.

Braun, V. and Clarke, V. (2014), "What can 'thematic analysis' offer health and wellbeing researchers? [Editorial]”, International Journal of Qualitative Studies on Health and Well-Being, Vol. 9, doi: 10. 3402/qhw.v9.26152 (accessed 17 January 2020).

Bryant, C.A. (2006), "Nursing the adopted infant", Journal of the American Board of Family Medicine, Vol. 19 No. 4, pp. 374-9, doi: 10.3122/jabfm.19.4.374 (accessed 17 January 2020).

Da Rocha, S., Meneses, I.M. and Nazareth, I.V. (2014), "Narratives of lives of women who breastfed their adoptive children", Revista Rene, Vol. 15 No. 2, pp. 249-256.

Ezura Madiana, M.M., Ahmad Yunus, M.N. and Nor Kamariah, M.A. (2015), "Beyond the milk dropsinduced lactation for adopted child at susuibu.com”, Brunei International Medical Journal, Vol. 11 No. 3, p. 27, available at: http://www.bimjonline.com/ (accessed 17 January 2020).

Flores-Antón, B., García-Lara, N.R. and Pallás-Alonso, C.R. (2017), "An adoptive mother who became a human milk donor", Journal of Human Lactation, Vol. 33 No. 2, pp. 419-421, doi: 10.1177/ 0890334416682007 (accessed 17 January 2020).

Goldfarb, L. (2009), An Assessment of the Experiences of Women Who Induced Lactation, Union Institute and University Cincinnati, Ohio.

Gribble, K.D. (2004), "The influence of context on the success of adoptive breastfeeding: developing countries and the west", Breastfeeding Review, Vol. 12 No. 1, pp. 5-13.

Gribble, K.D. (2007), “A model for caregiving of adopted children after institutionalization”, Journal of Child and Adolescent Psychiatric Nursing, Vol. 20 No. 1, pp. 14-26, doi: 10.1111/j.1744-6171.2007. 00076.x (accessed 17 January 2020).

Hormann, E. (1977), "Breastfeeding the adopted baby", Birth and the Family Journal, Vol. 4 No. 4, pp. $165-173$. 
$\mathrm{BFJ}$

122,10

3062

International Board of Certified Lactation Consultants (IBCLC) Malaysia (2015), "Breastfeeding issues: woman fiqh television program", The Malaysian Lifestyle Media, available at: http://www. mmgazette.com/kenyataan-rasmi-perunding-laktasi-malaysia-ibclc-berhubung-isu-penyusuanibu-dalam-rancangan-fiqh-wanita-tv3-782015/ (accessed 15 January 2020).

Kallio, H., Pietilä, A.M., Johnson, M. and Kangasniemi, M. (2016), "Systematic methodological review: developing a framework for a qualitative semi-structured interview guide", Journal of Advanced Nursing, Vol. 72 No. 12, pp. 2954-2965.

Kinga, A.S., Sherry, E.A. and Marc, B.R. (2010), "Induced lactation and exclusive breast milk feeding of adopted premature twins", Journal of Human Lactation, Vol. 26 No. 3, pp. 309-313, doi: 10. 1177/0890334410371210 (accessed 17 January 2020).

Lommen, A. and Brown, B. (2015), "Experiential perceptions of relactation: a phenomenological study", Journal of Human Lactation, Vol. 31 No. 3, pp. 498-503.

National Lactation Centre (2014), Data on Induced Lactation Year, Ministry of Health Malaysia, Selangor, 2014. 2 p. Reports No.: NLC2013-001.

National Lactation Centre (2015), Data on Induced Lactation Year, Ministry of Health Malaysia, Selangor, 2015. 2 p. Reports No.: NLC2014-001.

National Lactation Centre (2016), Data on Induced Lactation Year, Ministry of Health Malaysia, Selangor, 2016. 2 p. Reports No.: NLC2015-001.

National Registration Department (2012), Data on Application Adoption, Ministry of Home Affairs Malaysia, 2012, available at: http://www.jkm.my (accessed 17 January 2020).

Norsyamlina, C.A.R., Zaharah, S. and Tengku Alina, T.I. (2017), "The availability of information on induced lactation in Malaysia”, Malaysian Journal of Medical Sciences, Vol. 24 No. 4, pp. 5-17, doi: 10.21315/mjms2017.24.4.2 (accessed 17 January 2020).

Ritchie, J. and Lewis, J. (2003), Qualitative Research Practice: A Guide for Social Science Students and Researchers, 1st ed., Sage, London.

Sharan, H., Yahav, J., Peleg, D., Ben-Rafael, Z. and Merlob, P. (2001), "Hospitalization for early bonding of the genetic mother after a surrogate pregnancy: report of two Cases", Birth, Vol. 28 No. 4, pp. 270-273.

Social Welfare Statistics Report (2016), Ministry of Women, Family and Community Development Malaysia, 2015, available at: http://www.jkm.my (accessed 18 February 2020).

Social Welfare Statistics Report (2017), Ministry of Women, Family and Community Development Malaysia, 2016, available at: http:/www.jkm.my (accessed 18 February 2020).

Szucs, K.A., Axline, S.E. and Rosenman, M.B. (2010), "Induced lactation and exclusive breast milk feeding of adopted premature twins", Journal of Human Lactation, Vol. 26 No. 3, pp. 309-313, doi: 10.1177/0890334410371210 (accessed 17 January 2020).

Thearle, M.J. and Weissenberger, R. (1984), "Induced lactation in adoptive mothers", Journal of Obstetrics and Gynaecology, Vol. 24, pp. 283-286.

Wittig, S.L., Nurse, S. and Spatz, D.L. (2008), "Induced lactation: gaining a better understanding", The American Journal of Maternal Child Nursing, Vol. 33 No. 2, pp. 76-81.

World Health Organization/UNICEF (2017), Tracking Progress for Breastfeeding Policies and Program: Global Breastfeeding Scorecard 2017, World Health Organization, Geneva, Switzerland, available at: https://www.who.int/nutrition/publications/ infantfeeding/global-bfscorecard-2017.pdf?ua $=1$ (accessed 22 January 2020).

Zilal, S. and Farahwahida, M.Y. (2014), "Induced lactation by adoptive mothers: a case study", Journal of Technology (Sciences and Engineering), Vol. 68 No. 1, pp. 123-132.

Zilal, S., Farahwahida, M.Y., Norsyamlina, C.A.R., Shahrel Ahmad, S.A. and Siti Norlina, M. (2017), "Guidelines model of adoptive breastfeeding for Muslim foster mother among the Malay community in Malaysia”, International Journal of Islamic Studies, Vol. 8 No. 5, pp. 42-50. 
Zilal, S., Norsyamlina, C.A.R., Farah Safura, M., Farahwahida, M.Y. and Siti Norlina, M. (2018), "External success factors for induced lactation among non-puerperal adoptive mothers in Malaysia”, International Journal of Islamic Studies, Vol. 12 No. 3, pp. 30-38, available at: http:// myjms.mohe.gov.my/index.php/alqanatir (accessed 17 January 2020).

\section{Further reading}

Cheales-Siebenaler, N.J. (1999), "Induced lactation in an adoptive mother", Journal of Human Lactation, Vol. 15, pp. 41-43.

Gabay, M.P. (2002), "Galactogogues: medications that induce lactation”, Journal of Human Lactation, Vol. 18 No. 3, pp. 274-279.

\section{Corresponding author}

Zaharah Sulaiman be contacted at: zaharah@usm.my

For instructions on how to order reprints of this article, please visit our website: 